\title{
An IgA1-lambda-type monoclonal immunoglobulin deposition disease associated with membranous features in a patient with lgG4-related kidney disease: a case report
}

\author{
Atsushi Kitazawa ${ }^{1,2^{*}}$, Ryo Koda ${ }^{1}$, Atsunori Yoshino ${ }^{1}$, Yoshihiko Ueda ${ }^{2}$ and Tetsuro Takeda ${ }^{1}$
}

\begin{abstract}
Background: IgG4-related disease (IgG4-RD) is a newly recognized fibroinflammatory condition. The kidney is one of the organs commonly affected by lgG4-RD. Tubulointerstitial nephritis (TIN) is the main feature, and membranous nephropathy (MN) has also been described frequently. In MN, polyclonal immunoglobulins and complements are deposited in granular form along the glomerular basement membranes (GBMs). Unusual cases of monoclonal immunoglobulin deposition disease (MIDD) associated with membranous features have been reported. MIDD is morphologically similar to MN but contains immunoglobulins considered to be derived from single B-cell clone.

Case presentation: We describe a 65-year-old man who was referred to our hospital because of hyperproteinaemia, eosinophilia, anaemia, and proteinuria. A renal biopsy demonstrated infiltration of plasma cells and eosinophils in the interstitium, and the ratio of IgG4-positive plasma cells to lgG-positive plasma cells was 55\%. The patient was diagnosed as having IgG4-related TIN. Periodic acid methenamine silver staining under light microscopy revealed a bubbling appearance and spike formation in the GBM. On immunofluorescence, the expression of IgG and complements was negative; however, IgA was positively expressed in a granular pattern along the GBM. An IgA

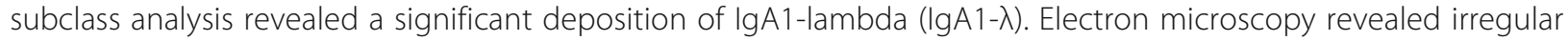
and small non-organized and non-Randall-type granular electron-dense deposits in the GBM that were shaped like snow leopard spots.

Conclusions: After corticosteroid therapy was initiated, the patient's eosinophilia remarkably improved and his serum creatinine, IgG, and lgG4 levels decreased to within the normal ranges. However, massive proteinuria persisted. To our knowledge, this is the first reported case of IgG4-related TIN associated with IgA1- $\lambda$-type MIDD with membranous features.
\end{abstract}

Keywords: IgG4-related disease, Monoclonal immunoglobulin deposition disease, Membranous nephropathy, Tubulointerstitial nephritis

\footnotetext{
* Correspondence: atsukitaaq@gmail.com

${ }^{1}$ Department of Nephrology, Dokkyo Medical University Saitama Medical

Center, 2-1-50 Minamikoshigaya, Koshigaya, Saitama 343-8555, Japan

${ }^{2}$ Department of Pathology, Dokkyo Medical University Saitama Medical

Center, 2-1-50 Minamikoshigaya, Koshigaya, Saitama 343-8555, Japan
}

(c) The Author(s). 2018 Open Access This article is distributed under the terms of the Creative Commons Attribution 4.0 International License (http://creativecommons.org/licenses/by/4.0/), which permits unrestricted use, distribution, and reproduction in any medium, provided you give appropriate credit to the original author(s) and the source, provide a link to the Creative Commons license, and indicate if changes were made. The Creative Commons Public Domain Dedication waiver (http://creativecommons.org/publicdomain/zero/1.0/) applies to the data made available in this article, unless otherwise stated. 


\section{Background}

Membranous nephropathy ( $\mathrm{MN}$ ) is defined as glomerulonephritis with a bubbling appearance and formation of spikes in the glomerular basement membrane (GBM) on light microscopy. On immunofluorescence, polyclonal immunoglobulins and complements are deposited in granular form along the glomerular basement membranes (GBMs). Only a few cases of non-organized and non-Randall-type monoclonal immunoglobulin deposition disease (MIDD) associated with membranous features have been reported in the literature $[1,2]$. MIDD is similar to $\mathrm{MN}$; however, on immunofluorescence, MIDD contains immunoglobulins restricted to a single immunoglobulin class, a single immunoglobulin subclass, and a single light chain, consistent with monoclonal proteins $[1,2]$.

On the other hand, IgG4-related disease (IgG4-RD) is recognized as a new chronic inflammatory disease characterized by elevated serum IgG4 levels, mass or tissue infiltration rich in IgG4-positive plasma cells, and storiform fibrosis [3].

The kidney is one of the organs commonly affected by IgG4-RD, and tubulointerstitial nephritis (TIN) with infiltration of numerous IgG4-positive plasma cells is the most common type of kidney lesion, and $\mathrm{MN}$ has been occasionally accompanied [4-6].

Here, we describe a patient with IgG4-related kidney disease who developed massive proteinuria due to membranous features associated with the deposition of IgA1-lambda (IgA1- $\lambda$ ) along the glomerular capillary walls.

\section{Case presentation}

A 65-year-old man was referred to our hospital because of hyperproteinaemia, eosinophilia, anaemia, and proteinuria after a 2-week history of slight fever, fatigue, and malaise.

On admission, his mental status was normal, body temperature was $36.5{ }^{\circ} \mathrm{C}$, pulse was $73 \mathrm{bpm}$ and regular, and blood pressure was 118/75 mmHg. A physical examination revealed eruption and oedema in his lower extremities; however, no abnormal signs were observed in the lungs, heart, or abdomen. His lymph node and thyroid gland were not swollen. The laboratory findings on admission are summarized in Table 1 . In brief, the eosinophil count was markedly increased (50\%). The IgG and IgG4 levels were markedly increased (6380 and $2430 \mathrm{mg} / \mathrm{dL}$, respectively). Urinalysis revealed massive proteinuria (3.5 g/ day) with haematuria (5-10 per high-power field), and the $\beta 2$-microglobulin level was $2863 \mathrm{ng} / \mathrm{mL}$. Chest radiography revealed ground-glass opacities in the lower lung field. Chest computed tomography (CT) revealed bronchial wall thickening and ground-glass opacities in the right middle and lower lobes of the lung. Abdominal CT revealed bilateral renal enlargement.

A renal biopsy was performed. Light microscopy revealed 3 global scleroses and no crescent within the 9

Table 1 Laboratory findings on admission

\begin{tabular}{|c|c|c|c|c|c|}
\hline \multicolumn{2}{|l|}{ Urinalysis } & \multicolumn{2}{|c|}{ Blood chemistry } & \multicolumn{2}{|c|}{ Immuno-serological findings } \\
\hline Pro. & $(3+)$ & TP & $10.3 \mathrm{~g} / \mathrm{dL}$ & CRP & $1.6 \mathrm{mg} / \mathrm{dL}$ \\
\hline Glu. & $(-)$ & Alb & $2.2 \mathrm{~g} / \mathrm{dL}$ & $\lg G$ & $6380 \mathrm{mg} / \mathrm{dL}$ \\
\hline Ket. & $(-)$ & T-bil & $0.8 \mathrm{mg} / \mathrm{dL}$ & $\lg A$ & 90 mg/dL \\
\hline Occult blood & $(2+)$ & AST & $21 \mathrm{IU} / \mathrm{L}$ & $\lg M$ & $42 \mathrm{mg} / \mathrm{dL}$ \\
\hline Sed. & & ALT & $11 \mathrm{IU} / \mathrm{L}$ & $\lg \mathrm{E}$ & $1480 \mathrm{IU} / \mathrm{mL}$ \\
\hline RBC & 10-19/HPF & LDH & $191 \mathrm{IU} / \mathrm{L}$ & $\lg G 4$ & $2430 \mathrm{mg} / \mathrm{dL}$ \\
\hline WBC & $5-9 / \mathrm{HPF}$ & ALP & $265 \mathrm{IU} / \mathrm{L}$ & C3 & 56 mg/dL \\
\hline Cast & $(+)$ & Y-GTP & $24 \mathrm{IU} / \mathrm{L}$ & C4 & $4.5 \mathrm{mg} / \mathrm{dL}$ \\
\hline Bence-Jones protein & $(-)$ & BUN & $27 \mathrm{mg} / \mathrm{dL}$ & Anti-nuclear-Ab & $(-)$ \\
\hline$C B C$ & & $\mathrm{Cr}$ & $1.4 \mathrm{mg} / \mathrm{dL}$ & MPO-ANCA & $(-)$ \\
\hline WBC & $9300 / \mu \mathrm{L}$ & $\mathrm{Na}$ & 133 mEq/L & PR3-ANCA & $(-)$ \\
\hline (polys) & $35 \%$ & K & $4.7 \mathrm{mEq} / \mathrm{L}$ & Cryoglobulin & $(-)$ \\
\hline (lym) & $13 \%$ & $\mathrm{Cl}$ & $105 \mathrm{mEq} / \mathrm{L}$ & IEP & $(-)$ \\
\hline (mono) & $2 \%$ & $\mathrm{Ca}$ & 8.1 mg/dL & FLC $k / \lambda$ retio & 1.35 \\
\hline (eosino) & $50 \%$ & IP & $4.3 \mathrm{mg} / \mathrm{dL}$ & HBs-Ag & $(-)$ \\
\hline RBC & $314 \times 104 / \mu \mathrm{L}$ & UA & $7.1 \mathrm{mg} / \mathrm{dL}$ & HCV-Ab & $(-)$ \\
\hline $\mathrm{Hb}$ & $9.4 \mathrm{~g} / \mathrm{dl}$ & CK & $28 \mathrm{IU} / \mathrm{L}$ & T-spot & $(-)$ \\
\hline $\mathrm{Ht}$ & $28.2 \%$ & TSH & $4.23 \mu \mathrm{U} / \mathrm{ml}$ & & \\
\hline Plt & $25.4 \times 104 / \mu \mathrm{L}$ & FT4 & 0.99 ng/dl & & \\
\hline
\end{tabular}


glomeruli. In the interstitium, severe infiltration of plasma cells and eosinophils, with storiform fibrosis and infiltration of numerous IgG4-positive plasma cells (IgG4-/IgG-positive plasma cell ratio $>50 \%$ ) were observed (Fig. 1a, b). In the functioning glomeruli, the GBM had a bubbling appearance with spikes but without significant mesangial cell or matrix proliferation (Fig. 1c). Direct fast scarlet staining was negative.

On immunofluorescence, the expression of IgG and complements was negative; however, IgA was positively expressed in a granular pattern along the GBM. An IgA subclass analysis revealed significant monoclonal deposition of IgA1- $\lambda$ (Fig. 2). We cut the frozen sections of renal biopsy specimens several times for other purposes such as immunostaining. Therefore, the last cut section was used for IgA subclass analysis, and there were few residual tissues and only an obliquely cut segment of the glomerulus remained. For this reason, we believe that it seemed that only a segment of the glomerulus stained with IgA1. Immunofluorescence staining for antibodies to M-type phospholipase A2 receptor (PLA2R) was negative (data not shown).

Electron microscopy revealed GBM thickening, widespread podocyte effacement, and irregular and small non-organized and non-Randall-type granular electrondense deposits in the GBM (Fig. 3) that were shaped like snow leopard spot-like pattern. On the basis of these findings, the diagnosis was IgA1-lambda-type non-Randall monoclonal immunoglobulin deposition disease associated with membranous features in a patient with IgG4-related TIN, according to the criteria for IgG4-RD [1]. Corticosteroid therapy was initiated with 3 days of $500 \mathrm{mg}$ intravenous methyl-prednisolone, followed by $40 \mathrm{mg} /$ day prednisolone. After the treatment, the oedema, eruption, and eosinophilia remarkably improved immediately. The serum creatinine level decreased to $1.0 \mathrm{mg} / \mathrm{dL}$, and IgG and IgG4 levels decreased to within their normal ranges. However, massive proteinuria persisted.

\section{Discussion and conclusions}

IgG4-RD is a recently recognized systemic immune-mediated disease, typically characterized by mass-forming fibroinflammatory lesions. IgG4-RD is well recognized in the form of TIN (IgG4-related TIN), which may present marked infiltration of lymphocytes and IgG4-positive plasma cells into the renal interstitium with interstitial fibrosis and minor glomerular lesions $[7,8]$.

However, several case reports have described IgG4-RD showing glomerular changes, of which MN is the most common. $\mathrm{MN}$ is present in approximately $7 \%$ of patients with IgG4-related TIN [9].

In MN associated with IgG4-RD, positive deposition of IgG4 without light-chain monoclonality in the GBM has been observed, either predominantly or together with other IgG subclasses [5, 9-12]. MN secondary to IgG4-RD is termed 'IgG4-related MN' [3], although primary $\mathrm{MN}$ is recognized to also have a dominant positive deposition of IgG4 in the GBM. Thus, immunostaining for IgG subclasses would likely not distinguish between primary $\mathrm{MN}$ and IgG4-related MN.

Alexander et al. reported that the glomerular staining tests for anti-PLA2R in 8 biopsies of $\mathrm{MN}$ in the setting of IgG4-RD were all negative. Thus, they argued that IgG4-related $\mathrm{MN}$ is a secondary $\mathrm{MN}$ [5]. In our case, glomerular staining for anti-PLA2R in biopsy was also negative.

In the present case, although serum IgG and IgG4 levels were elevated beyond the physiological level, routine techniques failed to detect an underlying B-cell disorder, with negative serum and urine protein immunoelectrophoresis and a normal free light chain (FLC) ratio. In Brief, the present case was compatible with IgG4-related kidney disease, however bone marrow examinations were not performed, so the possibility of hematological disorders could not be completely denied.

According to the systematic review of 37 cases of IgG4-related kidney disease [6], the serum IgG and IgG4

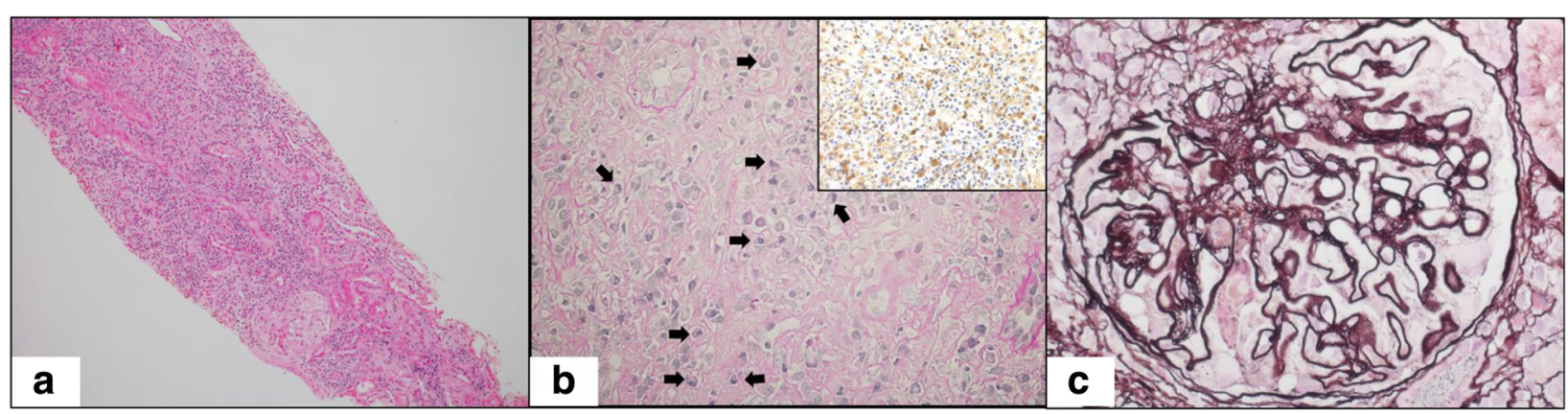

Fig. 1 Light microscopy findings of the renal biopsy specimen. a Interstitium showing extensive plasma cell infiltration, partial accumulation of eosinophils, and lymphocytes (haematoxylin-eosin staining, original magnification $\times 100$ ). b Interstitium showing plasma cell infiltration (arrow) and storiform fibrosis with tubule atrophy (periodic acid-Schiff staining, original magnification $\times 400$ ). Marked increase in IgG4-positive plasma cells was seen in the infiltrate (immunofluorescence staining for lgG4, original magnification $\times 400$ ). c The glomeruli showing spike formation and bubbling on the glomerular capillary walls (periodic acid methenamine silver-Masson trichrome, original magnification $\times 1000$ ) 


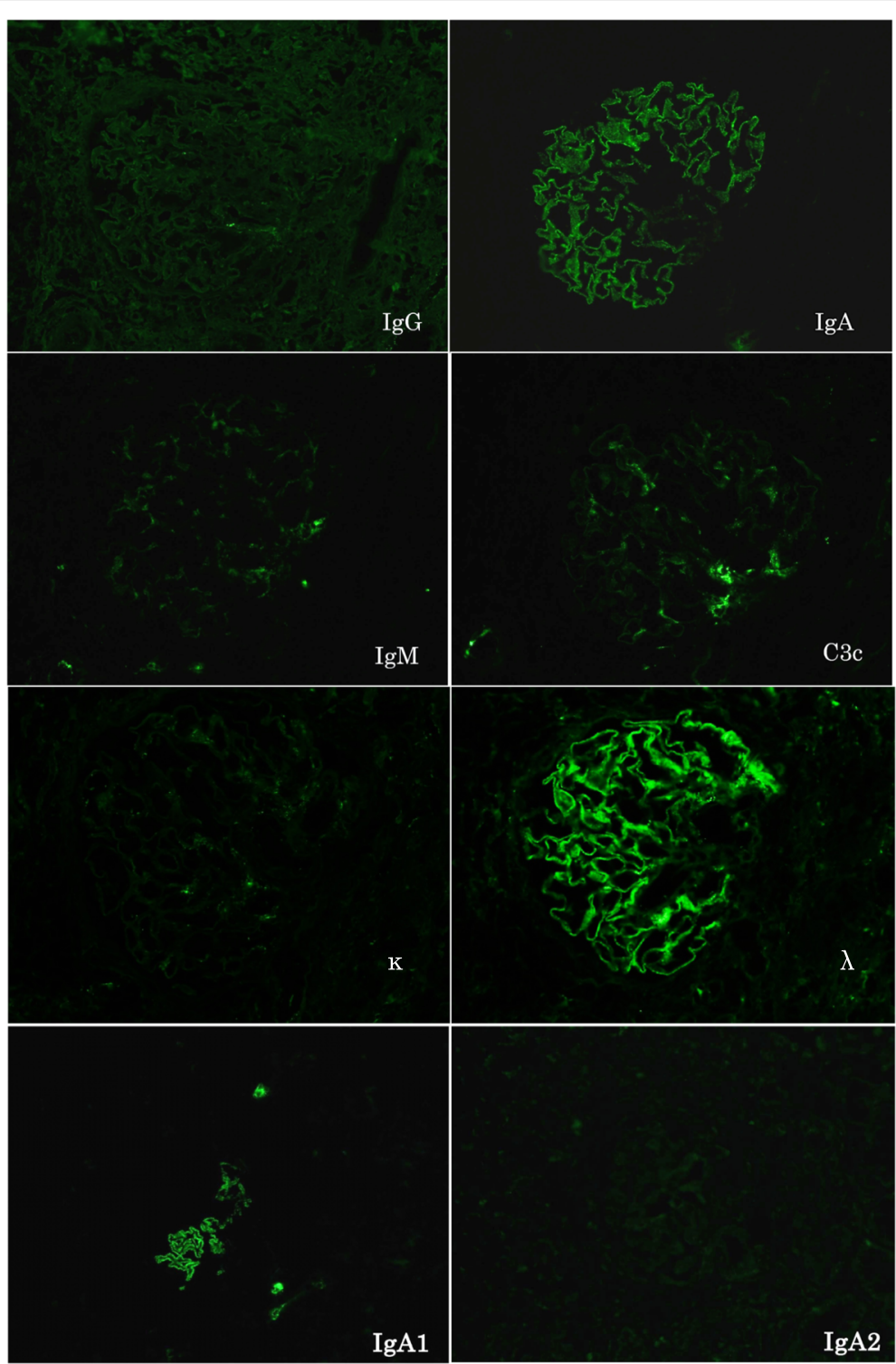

Fig. 2 Immunofluorescence microscopy image for the IgG heavy chain; $\mathrm{k}$-light chain; $\lambda$-light chain; C3; and lgG heavy-chain subclasses of lgG1, $\lg 62, \lg G 3, \lg G 4, \lg A 1$, and $\lg A 2$. Granular staining of $\lg A$ heavy chain dominant for $\lg A 1$ and $\lambda$-light chain along the glomerular capillary walls is shown (original magnification $\times 400$ )

levels were elevated to $1920-8194 \mathrm{mg} / \mathrm{dL}$ and 221-4630 $\mathrm{mg} / \mathrm{dL}$, respectively. Most cases of IgG4-related kidney disease show no elevation of IgM and IgA. However, IgM and IgA levels usually increase in TIN associated with autoimmune and inflammatory diseases. This is an important differential point. In the present case, the IgG level was $6380 \mathrm{mg} / \mathrm{dL}$, IgG4 level was $2430 \mathrm{mg} / \mathrm{dL}$, and IgA level was not elevated.

We did not examine viral antibodies such as Epstein-Barr virus and human herpesvirus-8; however, liver function was normal and atypical lymphocytes were not observed. Splenomegaly was not observed and the lymph nodes were not swollen; thus, it is unlikely that the patient had those viral infections.

CT scan did not reveal splenomegaly and lymphadenopathy. Moreover, there were no abnormal findings in the pancreas, salivary gland, and parotid.

IgG4-RD can be complicated with Sjogren syndrome or multicentric Castleman disease (MCD), and some cases are difficult to differentially diagnose.

The underlying premise is that the histological features (dense lymphoplasmacytic infiltrate and fibrosis, arranged at least focally in a storiform pattern) 


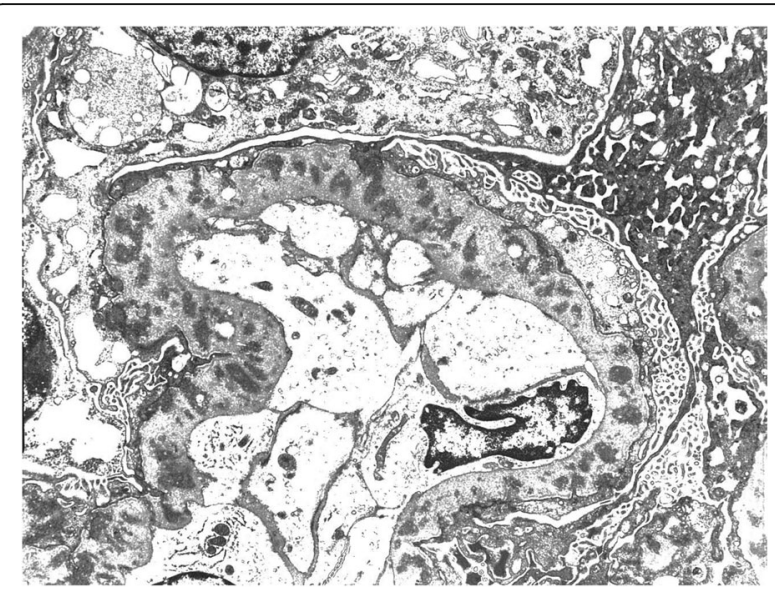

Fig. 3 Electron microscopy image showing granular electron-dense deposits without organized structures in the basement membrane

associated with IgG4-RD are highly specific when viewed in conjunction with IgG4 staining [13].

The presence of an atopic history is characteristic of IgG4-RD, whereas intense inflammation and polyclonal hyperimmunoglobulinaemia are characteristics of MCD. Moreover, IgA and C-reactive protein (CRP) levels are significantly higher in MCD than in IgG4-RD [14].
In the present case, the IgA level was not elevated and the CRP level was $1.6 \mathrm{mg} / \mathrm{dL}$. Moreover, also consistent with IgG4-RD, the IgG, IgG4, and complement levels promptly returned to the normal ranges after corticosteroid use.

In 2004, Nasr et al. first described proliferative glomerulonephritis with monoclonal IgG deposits (PGNMID), a newly characterized form of glomerulonephritis related to monoclonal IgG deposition that could not be assigned to any of the established categories of glomerular diseases. The glomerular deposits appeared primarily granular, resembling ordinary immune complex deposits but contained immunoglobulins considered to be derived from single $B$ cell clone. They classified the disease, according to the pattern of proliferative changes on light microscopy, as membranous proliferative glomerulonephritis, endocapillary proliferative glomerulonephritis, mesangial proliferative glomerulonephritis, and membranous glomerulonephritis [1].

Recently, Komatsuda et al. reported 3 patients with PGNMID with membranous features (2 IgG3-K and 1 IgG1-k) [2]. The condition was named 'non-Randall MIDD' because PGNMID with membranous features are poor in proliferative changes.

Eighteen cases of non-Randall MIDD with membranous features have been reported (Table 2), and IgG

Table 2 Summary of Reported Cases of Non Randal Monoclonal Immunoglobulin Deposition Disease with Membranous Features

\begin{tabular}{|c|c|c|c|c|c|c|c|c|c|c|}
\hline & & First author & age & $\operatorname{sex}$ & IEP & IF & EM & Aetiology & treatment & outcome \\
\hline 1 & 2003 & Touchard [20] & 48 & M & no & $\lg G 3 \lambda$ & subepi, subendo, mes & Idiopathic & PSL, Melphalan & remission \\
\hline 2 & 2003 & Evans [21] & 81 & $\mathrm{~F}$ & $\mathrm{n} / \mathrm{a}$ & $\operatorname{lgG} 1 \mathrm{k}$ & subepi & ML (B cell) & PSL, CY, Chlorambucil & dead \\
\hline 3 & 2004 & Nasr [1] & 63 & $\mathrm{~F}$ & $\lg G \lambda$ & $\lg G 1 \mathrm{~K}$ & subepi, subendo, mes & Idiopathic & & $\mathrm{n} / \mathrm{a}$ \\
\hline 4 & & & 42 & M & no & $\operatorname{lgG} 1 \mathrm{k}$ & subepi, subendo & Idiopathic & PSL & decreased proteinuria \\
\hline 5 & 2008 & Komatsuda [2] & 44 & M & no & $\operatorname{lgG} 3 k$ & subepi & Idiopathic & mPSL, PSL & decreased proteinuria \\
\hline 6 & & & 24 & M & no & $\operatorname{lgG} 3 k$ & subepi, subendo, mes & Idiopathic & PSL & decreased proteinuria \\
\hline 7 & 2010 & Miura [15] & 61 & M & no & $\lg A 1 \lambda$ & subepi & $\mathrm{HCV}$, cancer & Operation, Anti-tumor drug & no change \\
\hline 8 & 2010 & de Seigneux [22] & 62 & $\mathrm{~F}$ & $\lg G \lambda$ & $\lg G 1 \lambda$ & subepi, subendo & MGUS & Dexamethasone, Thalidomide & remission \\
\hline 9 & & & $\mathrm{n} / \mathrm{a}$ & $\mathrm{n} / \mathrm{a}$ & no & $\operatorname{lgG} 1 \mathrm{k}$ & $n / a$ & CLL & CY, Fludarabine & remission \\
\hline 10 & & & $\mathrm{n} / \mathrm{a}$ & $\mathrm{n} / \mathrm{a}$ & no & $\operatorname{lgG} 1 \mathrm{k}$ & $\mathrm{n} / \mathrm{a}$ & Unknown & PSL & ESRD \\
\hline 11 & 2011 & Guiard [23] & $\mathrm{n} / \mathrm{a}$ & $\mathrm{n} / \mathrm{a}$ & $\lg G \lambda$ & $\lg G 1 \lambda$ & $\mathrm{n} / \mathrm{a}$ & MM & PSL, Melphalan & remission \\
\hline 12 & & & $\mathrm{n} / \mathrm{a}$ & $\mathrm{n} / \mathrm{a}$ & no & $\operatorname{lgG} 2 k$ & $n / a$ & Unknown & Rituximab & remission \\
\hline 13 & & & $\mathrm{n} / \mathrm{a}$ & $\mathrm{n} / \mathrm{a}$ & no & $\lg G 3 k$ & $\mathrm{n} / \mathrm{a}$ & Unknown & PSL, CY & remission \\
\hline 14 & & & $n / a$ & $\mathrm{n} / \mathrm{a}$ & no & $\operatorname{lgG} 3 k$ & $\mathrm{n} / \mathrm{a}$ & Unknown & Rituximab & decreased proteinuria \\
\hline 15 & 2012 & Yamada [24] & 63 & M & no & $\lg G 1 \lambda$ & subepi & $\mathrm{HCV}$ & PSL, Mizoribine & decreased proteinuria \\
\hline 16 & 2012 & Ito [25] & 68 & $\mathrm{~F}$ & no & $\lg G 3 \lambda$ & subepi, mes & MPO-ANCA & PSL & remission \\
\hline 17 & 2013 & Ohashi [26] & 27 & $\mathrm{~F}$ & no & $\operatorname{lgG} 2 \mathrm{~K}$ & subepi, mes & Idiopathic & PSL & remission \\
\hline 18 & 2014 & Omokawa [16] & 62 & $\mathrm{~F}$ & no & $\operatorname{lgG} 4 k$ & subepi, mes & lgG4RD(lung) & mPSL, PSL & decreased proteinuria \\
\hline 19 & 2017 & Present case & 65 & M & no & $\lg A 1 \lambda$ & subepi & $\operatorname{lgG4RKD(TIN)}$ & PSL & no change \\
\hline
\end{tabular}

Abbreviations: $\mathrm{CY}$ cyclophosphamide, $E M$ electron microscopic study, $\mathrm{HCV}$ hepatitis $\mathrm{C}$ virus infection, IEP immunoelectrophoresis, IF immunofluorescent study, IgG4RD IgG4 related disease, IgG4RKD IgG4 related kidney disease, mes mesangial area, MGUS monoclonal gammopathy of undetermined significance, $M L$ malignant lymphoma, MM multiple myeloma, MPO-ANCA myeloperoxidase-anti-neutrophil cytoplasmic antibody, mPSL methylprednisolone, n/a: not available, PSL prednisolone, subendo subendothelial area, subepi subepithelial area, TIN tubulointerstitialnephritis 
subclass analysis along the GBM mostly showed IgG1 or IgG3. The presence of monoclonal gammopathy in the sera is rare.

Only one case of IgA1- $\lambda$-type monoclonal deposition with membranous features, which was associated with hepatitis $\mathrm{C}$ virus $(\mathrm{HCV})$ infection and rectal cancer, has been reported [15]. The electron-dense deposits in the GBM were also irregular and similar to our case. They were also shaped like snow leopard spots. However, our patient was HCV negative and had no malignancy in the past 4 years.

Another relevant interesting case was IgG4-RD associated with non-Randall MIDD with membranous features [16]. It was reported as IgG4-related lung disease associated with IgG4-k-type MIDD with membranous features but without tubulointerstitial change in the kidney. Steroid therapy was effective for both kidney and lung lesions. Thus, the authors mentioned possible common mechanisms in the formation of both IgG4-k-type MIDD with membranous features and IgG4-RD.

In IgG4-RD, the markedly high IgG4 levels may simply be a reflection of the response to some primary inflammatory stimuli [17]. T cells have recently been suggested to contribute to the pathogenesis of IgG4-RD. Some reports have indicated that the production of $\mathrm{T}$ helper (Th) 2 cytokines and regulatory T-cell cytokines is increased in patients with IgG4-RD. A recent study showed that the Th17 cell subset is also upregulated in patients with IgG4-RD [18]. These cytokines are suspected to be important in the pathogenesis of IgG4-RD.

In PGNMID, the pathogenesis remains elusive. Because up to two-thirds of patients with PGNMID have no detectable $M$ protein even after a long follow-up, Nasr et al. proposed that this unique glomerulonephritis may arise in the course of normal immune responses in these patients. During an immune response, 1 or more clones of B cells may proliferate and produce monoclonal IgG molecules with the ability to self-aggregate and rapidly deposit in the glomeruli [19].

In the present case, paraprotein in blood and urine was not detected by immunoelectrophoresis, and even in serum FLC assay, no deviation of the FLC ratio could be found. Therefore, 1 or more clones of B cells may have proliferated and produced monoclonal IgA molecules similarly to PGNMID.

Indeed, it is difficult to find a common mechanism between the 2 rare diseases, and they would not have a specific relationship.

IgG4-RD cause disorders of the basis of the immune response such as regulatory T-cell, and tend to cause other autoimmune diseases such as membranous nephropathy. However, it is unknown whether monoclonal immunoglobulin deposition increases as in the present case.
In summary, non-Randall MIDD with membranous features is rather rare, and only 1 case of monoclonal deposition from the IgA variant has been reported. To our knowledge, this is the first reported case of IgA1-lambda-type non-Randall monoclonal immunoglobulin deposition disease associated with membranous features in a patient with IgG4-related TIN.

\section{Abbreviations \\ CT: Computed tomography; GBM: Glomerular basement membrane; HCV: Hepatitis C virus; IgG4-RD: IgG4-related disease; MIDD: Monoclonal immunoglobulin deposition disease; MN: Membranous nephropathy; PGNMID: Proliferative glomerulonephritis with monoclonal IgG deposits; TIN: Tubulointerstitial nephritis}

\section{Acknowledgements}

We wish to thank Takuya Okamura (Department of Pathology, Dokkyo Medical University Saitama Medical Center, Saitama, Japan).

Funding

Not applicable.

\section{Availability of data and materials}

Not applicable.

\section{Authors' contributions}

RK and AY were the attending physicians during the hospitalization of the patient and at the outpatient clinic. AK wrote the manuscript. AK and YU performed the histopathological examination and obtained the diagnosis. Tा provided medical care during hospitalization and revised the manuscript. All authors have read the final version of this paper and approve its publication.

Ethics approval and consent to participate

Not applicable.

\section{Consent for publication}

Written informed consent was obtained from the patient for the publication of this case report including clinical information and related images. The consent form has been stored by the corresponding author and may be obtained on request from the editor of this journal.

\section{Competing interests}

The authors declare that they have no competing interests.

\section{Publisher's Note}

Springer Nature remains neutral with regard to jurisdictional claims in published maps and institutional affiliations.

Received: 24 March 2018 Accepted: 6 November 2018

Published online: 20 November 2018

\section{References}

1. Nasr SH, Markowitz GS, Stokes MB, et al. Proliferative glomerulonephritis with monoclonal IgG deposits: a distinct entity mimicking immune-complex glomerulonephritis. Kidney Int. 2004 Jan;65(1):85-96.

2. Komatsuda A, Masai R, Wakui H, et al. Monoclonal immunoglobulin deposition disease associated with membranous features. Nephrol Dial Transplant. 2008;23(12):3888-94.

3. Stone JH, Khosroshahi A, Deshpande V, et al. IgG4-related disease: recommendations for the nomenclature of this condition and its individual organ system manifestations. Arthritis Rheum. 2012;64:3061-7.

4. Saeki T, Nishi S, Imai N, et al. Clinicopathological characteristics of patients with IgG4-related tubulointerstitial nephritis. Kidney Int. 2010;78:1016-23.

5. Alexander MP, Larsen CP, Gibson LW, et al. Membranous glomerulonephritis is a manifestation of IgG4-related disease. Kidney Int. 2013;83:455-62.

6. Nishi S, Imai N, Yoshida K, et al. Clinicopathological findings of immunoglobulin G4-related kidney disease. Clin Exp Nephrol. 2011;15:810-9.

7. Raissian Y, Nasr SH, Larsen CP, et al. Diagnosis of IgG4-related tubulointerstitial nephritis. J Am Soc Nephrol. 2011 Jul;22(7):1343-52. 
8. Cornell LD, Chicano SL, Deshpande V, et al. Pseudotumors due to lgG4 immune-complex tubulointerstitial nephritis associated with autoimmune pancreatocentric disease. Am J Surg Pathol. 2007;31:1586-97.

9. Saeki T, Imai N, Ito T, et al. Membranous nephropathy associated with IgG4related systemic disease and without autoimmune pancreatitis. Clin Nephrol. 2009;71:173-8.

10. Fervenza FC, Downer G, Beck LH, et al. IgG4-related tubulointerstitial nephritis with membranous nephropathy. Am J Kidney Dis. 2011;58:320-4.

11. Palmisano A, Corradi D, Carnevali ML, et al. Chronic periaortitis associated with membranous nephropathy: clues to common pathogenetic mechanisms. Clin Nephrol. 2010;74:485-90.

12. Cravedi P, Abbate M, Gagliardini E, et al. Membranous nephropathy associated with lgG4-related disease. Am J Kidney Dis. 2011;58:272-5.

13. Deshpande V, Zen Y, Chan JK, et al. Consensus statement on the pathology of IgG4-related disease. Mod Pathol. 2012;25:1181-92.

14. Sasaki T, Akiyama M, Kaneko Y, et al. Distinct features distinguishing IgG4related disease from multicentric Castleman's disease. RMD Open. $2017 \mathrm{Ju}$ $18 ; 3(1)$.

15. Miura $\mathrm{N}$, Uemura $\mathrm{Y}$, Imai $\mathrm{H}$, et al. An IgA1-lambda-type monoclonal immunoglobulin deposition disease associated with membranous features in a patient with chronic hepatitis C viral infection and rectal cancer. Clin Exp Nephrol. 2010;14(1):90-3.

16. Omokawa A, Komatsuda A, Wakui H, et al. Membranous nephropathy with monoclonal lgG4 deposits and associated IgG4-related lung disease. Clin Kidney J. 2014;7(5):475-8.

17. Stone JH, Zen Y, Deshpande V. IgG4-related disease. N Engl J Med. 2012; 366:539-51.

18. Grados A, Ebbo M, Piperoglou C, et al. T cell polarization toward TH2/TFH2 and TH17/TFH 17 in patients with IgG4-related disease. Front Immunol. 2017:8:1-10.

19. Nasr SH. Proliferative glomerulonephritis with monoclonal lgG deposits. J Am Soc Nephrol. 2009 Sep;20(9):2055-64.

20. Touchard G. Ultrastructural pattern and classification of renal monoclonal immunoglobulin deposits. In: Touchard G, Aucouturier P, Hermine O, Ronco P, editors. Monoclonal Gammopathies and the kidney. Dordrecht: The Netherlands, Kluwer; 2003. p. 95-117.

21. Evans DJ, Macanovic M, Dunn MJ, Pusey CD. Membranous glomerulonephritis associated with follicular B-cell lymphoma and subepithelial deposition of IgG1-kappa paraprotein. Nephron Clin Pract. 2003;93:c112-8.

22. de Seigneux S, Bindi P, Debiec $H$, et al. Immunoglobulin deposition disease with a membranous pattern and a circulating monoclonal immunoglobulin $\mathrm{G}$ with charge-dependent aggregation properties. Am J Kidney Dis. 2010;56 $117-21$.

23. Guiard E, Karras A, Plaisier E, et al. Patterns of noncryoglobulinemic glomerulonephritis with monoclonal lgG deposits: correlation with IgG subclass and response to rituximab. Clin J Am Soc Nephrol. 2011;6:1609-16.

24. Yamada T, Arakawa Y, Mii A, et al. A case of monoclonal immunoglobulin G1-lambda deposition associated with membranous feature in a patient with hepatitis C viral infection. Clin Exp Nephrol. 2012;16:468-72.

25. Ito A, Miura N, Imai H, et al. Myeloperoxidase anti-cytoplasmic antibody

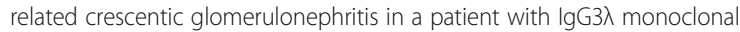
immunoglobulin deposition disease with membranous features. Intern Med. 2012:51(17):2393-7.

26. Ohashi R, Sakai Y, Shimizu A, et al. Proliferative glomerulonephritis with monoclonal IgG2K deposit successfully treated with steroids: a case report and review of the literature. CEN case report. 2013 Nov:2(2):197-203.

Ready to submit your research? Choose BMC and benefit from:

- fast, convenient online submission

- thorough peer review by experienced researchers in your field

- rapid publication on acceptance

- support for research data, including large and complex data types

- gold Open Access which fosters wider collaboration and increased citations

- maximum visibility for your research: over $100 \mathrm{M}$ website views per year

At BMC, research is always in progress.

Learn more biomedcentral.com/submissions 